\title{
Mechanical circulatory support: Technical tips for the implantation of a right ventricular assist device
}

Evgenij Potapov, MD, ${ }^{\mathrm{a}, \mathrm{b}}$ Christoph Starck, MD, ${ }^{\mathrm{a}, \mathrm{b}}$ Volkmar Falk, MD, ${ }^{\mathrm{a}, \mathrm{b}, \mathrm{c}, \mathrm{d}}$ and Jaime-Jürgen Eulert-Grehn, MD ${ }^{\text {a,b }}$

Small, implantable continuous-flow pumps were introduced into clinical practice in $1998 .{ }^{1}$ Conceptually designed as devices for bridge to transplantation, most devices are currently implanted as long-term support devices. ${ }^{2}$ Paracorporeal pumps, except in the pediatric population, are rarely used. Due to the limited availability and complexity of total artificial hearts (TAHs), these systems are almost exclusively used for patients in emergency settings with no other support option. As a result, there is a growing need for a continuous-flow biventricular assist device (cfBIVAD). Left ventricular assist device (LVAD) pumps, which were developed for supporting the systemic circulation, can also assist the right ventricle (RV). ${ }^{3} \mathrm{Up}$ to now, no commercially available implantable device is approved by the Food and Drug Administration or the European Medicines Agency for RV support, neither as isolated support of the $\mathrm{RV}$ nor in a biventricular mode. At the same time, the only commercially available device in the United States, the paracoroporeal Thoratec (Abbott Cardiovascular, Abbott Park, Ill) RV assist device (RVAD), has not been available for quite some time. The alternative is cardiectomy and implantation of the SynCardia (SynCardia Systems, Tucson, Ariz) TAH device or the Aeson TAH (Carmat, Vélizy-Villacoubay, France) device, which are both approved by the European Medicines Agency.

Long-term mechanical circulatory support has emerged as a subspecialty of cardiac surgery. In Germany, only 3 out of 77 heart centers perform more than 200 VAD operations annually, and only an additional 4 centers perform around 100 operations per year. Most surgeries involve

\footnotetext{
From the ${ }^{\mathrm{a} D e p a r t m e n t}$ of Cardiothoracic and Vascular Surgery, German Heart Center, Berlin, Germany; ' German Center for Cardiovascular Research Partner Site, Berlin, Germany; ${ }^{\mathrm{c} D e p a r t m e n t ~ o f ~ C a r d i o t h o r a c i c ~ S u r g e r y, ~ C h a r i t e ́ ~-~ U n i v e r s i t a ̈ t s m e d i-~}$ zin Berlin, Berlin, Germany; and ${ }^{\mathrm{d}}$ Section of Translational Cardiovascular Technologies, Institute of Translational Medicine, Department of Health Sciences and Technology, Swiss Federal Institute of Technology Zurich, Zurich, Switzerland.

Received for publication Aug 5, 2021; accepted for publication Sept 27, 2021; available ahead of print Oct 22, 2021.

Address for reprints: Evgenij Potapov, MD, Department of Cardiothoracic and Vascular Surgery, German Center for Cardiovascular Research, Augustenburger Platz 1, 13353 Berlin, Germany (E-mail: potapov@dhzb.de).

JTCVS Open 2021;8:37-40

2666-2736

Copyright (C) 2021 The Author(s). Published by Elsevier Inc. on behalf of The American Association for Thoracic Surgery. This is an open access article under the CC BY-NC-ND license (http://creativecommons.org/licenses/by-nc-nd/4.0/).

https://doi.org/10.1016/j.xjon.2021.09.046
}

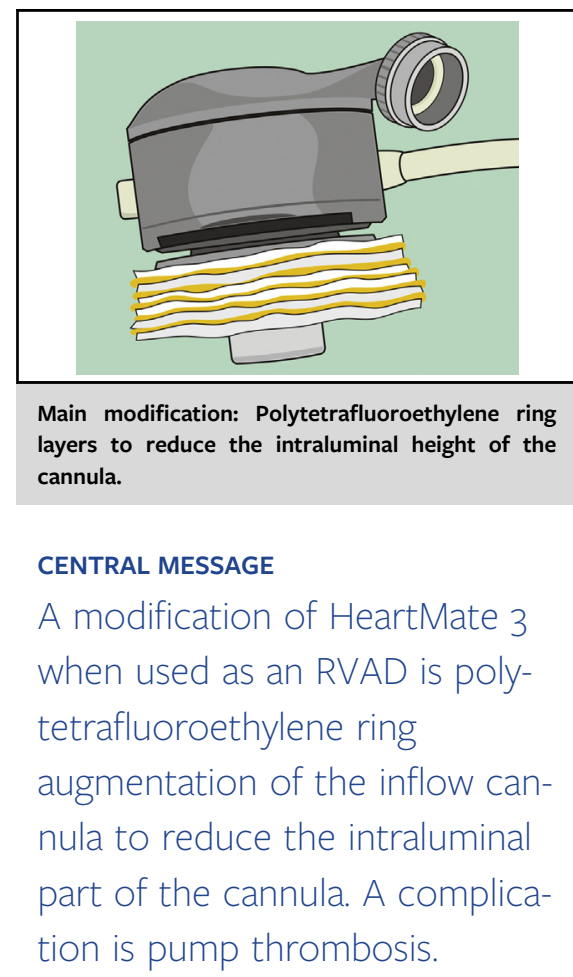

See Commentary on page 41.

the implantation of single-ventricle support devices. During this period, the use of cfBIVAD and TAH was almost negligible. Between 2013 and 2019, only 14 to 68 BIVADs were implanted annually. Of approximately 1000 long-term mechanical circulatory support systems implanted annually during the same period, only 7 to 27 per year were TAH implantations. $^{4}$

The differences between implantable cfBIVAD and TAH are presented in Table 1. No direct comparisons were ever performed in a trial, and hence Table 1 represents only an expert opinion on the available studies on cfBIVAD or TAH.

There are many reasons why a direct comparison between TAH and cfBIVAD and comparisons between different publications must be interpreted with caution. First, mortality is usually driven by the indication, as exemplified by the fact that $90 \%$ of deaths after TAH occur within the first 40 days. ${ }^{6}$ Second, the transplant rate differs considerably between regions. In Spain, with 47.3 million inhabitants, 321 cardiac transplants were performed during 
TABLE 1. Total artificial heart (TAH) and continuous-flow biventricular assist device (cfBIVAD)

\begin{tabular}{|c|c|c|}
\hline Variable & TAH & cfBIVAD \\
\hline 1-y survival & Similar* & Similar* \\
\hline Device function & Entirely dependent on device function & Partially dependent on device function \\
\hline $\begin{array}{l}\text { Successful resuscitation in case of } \\
\text { device malfunction }\end{array}$ & Not possible & $\begin{array}{l}\text { Possible, if residual function of } \\
\text { ventricles is present }\end{array}$ \\
\hline Suitable for small body sizes & No & Yes \\
\hline Suitable for small ventricles/restrictive cardiomyopathy & Yes & No \\
\hline
\end{tabular}

2018. ${ }^{7,8}$ In contrast, in Germany, with a population of 83.2 million; that is, nearly double the population of Spain, fewer cardiac transplants were performed, namely 318 heart and heart-lung transplants. ${ }^{4,8}$ In a multicenter report by Shah and colleagues, ${ }^{9} 43 \%$ patients initially treated with cfBIVAD received a heart transplant. In the largest singlecenter cfBIVAD report, the transplantation rate was $2.6 \% .{ }^{10}$ Overall, transplant rates and waiting list times in different regions can substantially influence the outcome of TAH and cfBIVAD reports.

The goal of this article is to present the indications for and surgical technique for implanting the HeartMate 3 (Abbott Cardiovascular) cfLVAD to support a failing RV. There are different indications for long-term RVAD:

- Early onset of RV failure immediately after LVAD implantation, treated by temporary RVAD. In selected cases a permanent solution is needed;

- Late onset of RV failure months or even years after LVAD implantation;

- Primary biventricular failure; and

- Isolated RV failure due to acute myocardial infarction, pulmonary hypertension, or rare diseases such as Uhl anomaly. ${ }^{11,12}$

All 4 indications call for the same implantation technique, namely either a right atrial (RA) or a RV implantation of the cfVAD inflow cannula and the outflow graft anastomosed to the pulmonary artery. The most common indication is post-LVAD early $\mathrm{RV}$ failure, whereas primary implantation was documented in $<0.1 \%$ of cases in a recent Society of Thoracic Surgeons (STS) Intermacs report. ${ }^{13}$

Estimating the rate of RV failure in cfLVAD patients is difficult because there is no commonly accepted definition and the reported rates are therefore not consistent. The Multi-center Study of MagLev Technology in Patients Undergoing MCS Therapy With HeartMate 3 randomized trial reported right heart failure in $34.2 \%$ of patients at 2 years, with $0.27 \%$ events per patient-year in patients with a HeartMate 3 device. ${ }^{14}$ It was found that $4.1 \%$ received an RV assist system. ${ }^{14}$ The 2019 STS Intermacs report shows freedom from right heart failure in $87 \%$ of the patients at 1 month, in $67 \%$ at 1 year, and in $62 \%$ at 2 years. ${ }^{13}$ Right heart failure is thus predominantly encountered during the first postoperative month. A closer look at a further analysis of the STS Intermacs data brings the role of RV support into perspective. From 2006 to 2017, 19,206 cfLVADs were implanted, compared with only 667 concomitant RVADs, meaning biventricular support. These included both temporary and permanent RVADs.

During the same period, 339 TAHs were implanted and 20 patients received an isolated RVAD. ${ }^{15}$ If we look at the long-term options for the surgical treatment of RV failure in patients with LV failure, 2 options exist beside heart transplantation: BIVAD support and TAH support. In contrast to cfBIVAD, the TAH devices SynCardia TAH and Aeson TAH are approved for patients with biventricular failure as bridge to transplantation. ${ }^{16,17}$ An important limitation of cfBIVADs is that they are not suitable for patients with restrictive cardiomyopathy.

The most extensively investigated TAH currently available for clinical use is the SynCardia TAH. An analysis of the Intermacs database between 2012 and 2014 reports a 1-year survival of $56 \%$ for cfBIVAD and of $59 \%$ for TAH. ${ }^{5}$

An important finding by Copeland and colleagues ${ }^{6}$ is that $90 \%$ of deaths after TAH implantation occur during the first 40 days. TAH was mostly used as a bridge to transplantation. Survival to transplantation was $68.3 \%$. Long-term data by Torregrossa and colleagues ${ }^{18}$ indicate that infections play a major role, with $50 \%$ of patients implanted with a TAH dying of multiorgan failure secondary to an infection. Shah and colleagues ${ }^{9}$ report multiorgan failure in $43 \%$ and sepsis in $13 \%$ of patients as major causes of death. $^{9}$ The extracorporeal part, even if small in patients with a cfBIVAD, is an entry port and therefore increases the risk of infection. It is important to mention that, in contrast to cfBIVADs, patients with a TAH are entirely dependent on device function. In the case of a device malfunction in patients with a cfBIVAD, it is still possible for the native heart to generate sufficient cardiac output until the device problem can be fixed. Another advantage is that patients with a cfBIVAD can still be successfully resuscitated because the native heart is still in place. This is not the case in patients with TAH. The notion of a better quality of life with cfBIVADs arises from the comparison of cfLVADs with paracorporeal LVADs in the landmark randomized trial with the axial-flow HeartMate 2 device. ${ }^{19}$ 
Whether or not this finding can be extrapolated to cfBIVADs and whether or not patients with cfBIVADs have a clinically meaningful better quality of life compared with patients with TAH was never investigated thoroughly.

A look at the meaningful differences in survival between patients with an LVAD compared with patients with a BIVAD could indicate that a patient's condition at the time of implantation is the main driver of long-term outcome. Patients with a cfBIVAD presented with a lower Intermacs profile: $93 \%$ of patients on BIVAD support had an Intermacs profile of 1 or 2 . In contrast, only $73 \%$ of LVAD patients were that sick. The survival curves diverged right from the beginning, with a 6-month survival rate of $86 \%$ for LVADs and of $56 \%$ for cfBIVADs. ${ }^{20}$

From a surgical point of view, secondary RVAD implantation usually means resternotomy. Depending on the interval between the LVAD implantation and the RVAD implantation, considerable adhesion may be encountered. For secondary RVAD implantations, median sternotomy is the most suitable access because the RA or the RV and the pulmonary trunk can easily be reached. In selected cases, bilateral thoracotomy is an alternative approach.

The HeartMate 3 pump is fully magnetically levitated and a low rotation speed can be safely used; therefore, narrowing of the outflow graft is not required for this pump. ${ }^{10}$ Although cfLVAD implantation is highly standardized and the inflow cannula is almost always placed in the apex of the LV, in case of using a continuous-flow pump for right heart support the inflow cannula and the pump may be implanted either into the RA or the RV. Due to the thinner wall and the smaller size compared with the LV, both approaches require ring augmentation to accommodate the roughly 32-mm long inflow cannula to the right side to prevent suction events.

This can easily be achieved through augmentation with polytetrafluoroethylene rings with the aim of leaving around 5 to $10 \mathrm{~mm}$ of the inflow cannula in the lumen of the RA or RV. Although this modification reduces the risk of suction events, the effects of tissue ingrowth may promote pump thrombosis. Usually, around 4 to 8 polytetrafluoroethylene strips are used for the HeartMate 3 inflow cannula (Figure 1). The rings were cut from a polytetrafluoroethylene plate, glued together with a fixation ring on top using BioGlue (Kennesaw, Ga), and then punched with the standard HeartMate 3 apex knife on the back table.

The optimal site for placing the inflow cannula remains a matter of debate and is often influenced by the anatomy of the patient, especially the distance of the heart to the chest and the degree of atrial and ventricular enlargement. We, as well as many other centers, prefer atrial placement of the RVAD cannula. ${ }^{20}$ The optimal site should be evaluated by transesophageal echocardiogram while imprinting the site of cannula placement with an index finger. The site should be as far as possible from the interatrial septum and directed

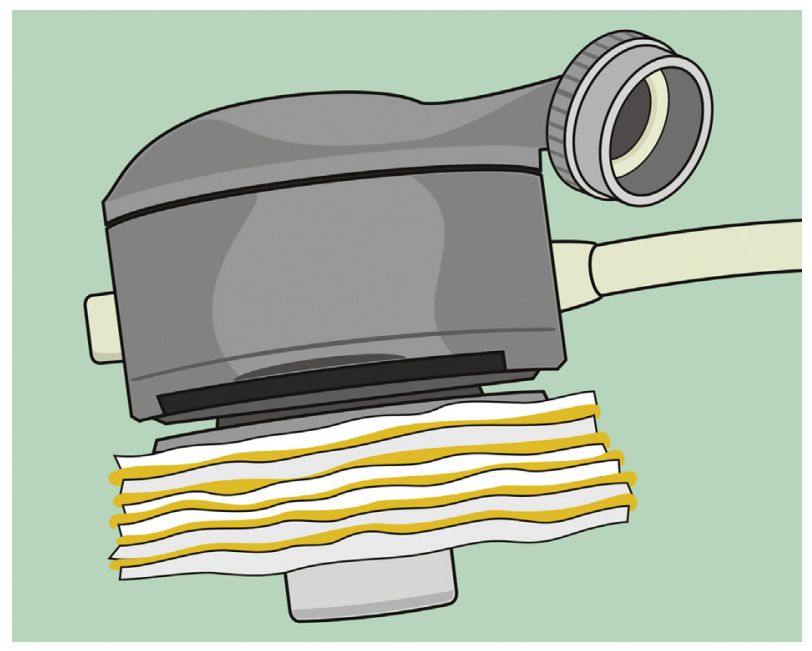

FIGURE 1. Inflow cannula augmentation with polytetrafluoroethylene rings, leaving around 5 to $10 \mathrm{~mm}$ in the lumen of the right atrium or ventricle, respectively.

toward the tricuspid valve. In patients with RV failure, the RA is usually enlarged; therefore, we do not recommend resecting the tricuspid valve. Together with the augmentation rings, the fixation ring is attached to the RA or RV using 12 interrupted pledgeted sutures. The length of the outflow graft should be kept short; therefore, we usually use a diamond-shaped anastomosis to create a $90^{\circ}$ anastomosis with the pulmonary artery.

We recommend keeping the outflow graft of the RVAD short by anastomosing $90^{\circ}$ to the pulmonary artery. In this case, in some patients the bend relief may be shortened. However, because the RVAD graft runs exactly behind the manubrium sterni, the bend relief would protect it during resternotomy (eg, for heart transplant). Therefore, we do not recommend removing it completely.

Suction events can lead to thrombus formation, and RVAD pump thrombosis is the Achilles' heel of cfBIVAD support with rates of pump thrombosis ranging between $30 \%$ and $37 \%$ in early reports. ${ }^{9,10,21,22}$ Shehab and colleagues $^{21}$ reported a lower rate of pump thrombosis for the RA compared with the RV configuration. It remains to be proven whether or not placement of a cava filter or use of the HeartMate 3, with its known improved hemocompatibility, can reduce the rate of pump thrombosis in cfBIVADs. A multicenter report and a recent single-center report with 2 HeartMate 3 devices showed a much lower rate of RVAD pump thrombosis, ranging between $7 \%$ and $20 \%$. $^{23,24}$

In patients at higher risk for RV failure or intraoperative beginning right heart failure after cfLVAD implantation, we implant a temporary RVAD and start weaning the RVAD at the fifth postoperative day. We decrease the temporary RVAD flow steadily by $0.5 \mathrm{~L} /$ minute daily. When the patient is stable with a temporary RVAD flow of $2 \mathrm{~L} /$ minute we 
perform a pump stop echocardiogram. Then we decide whether or not a permanent RVAD is needed. Otherwise, the temporary RVAD can be explanted.

\section{CONCLUSIONS}

The global experience with continuous-flow biventricular support is still very limited but growing. The approach is certainly feasible. Outcomes are largely driven by the indication and the subsequent transplantation rate. Because pump thrombosis appears to be emerging as the main complication, strategies to reduce this event, such as the atrial approach, will be crucial. With the improved hemocompatibility of the HeartMate 3 pump, there is hope for a further decrease in the rate of pump thrombosis for biventricular support.

\section{Conflict of Interest Statement}

Dr Potapov has received fees for lectures and presentations and travel grants from Abbott and are on the advisory board for Medtronic. Dr Starck has received research and educational grants, consulting fees, fees for lectures and speeches, travel grants, and have participated in the data safety monitoring board or advisory board for Cook Medical; received consulting fees and have participated in a data safety monitoring board or advisory board for Biotronik; received consulting fees from Andiodynamics; have received payment or fees for lectures or presentations from Abiomed; and are stockholders in Boston Scientific. Dr Falk has received educational grants (including travel support), fees for lectures and speeches, fees for professional consultations, and research and study funds from Abbott, Medtronic, JOTEC/CryoLife, Boston Scientific, Edwards, Novartis, Berlin-Heart, Zurich-Heart, and Biotronik. Dr Eulert-Grehn reported no conflicts of interest.

The Journal policy requires editors and reviewers to disclose conflicts of interest and to decline handling or reviewing manuscripts for which they may have a conflict of interest. The editors and reviewers of this article have no conflicts of interest.

\section{References}

1. Potapov EV, Loebe M, Nasseri BA, Sinawski H, Koster A, Kuppe H, et al. Pulsatile flow in patients with a novel nonpulsatile implantable ventricular assist device. Circulation. 2000;102(19 Suppl 3):III183-7.

2. Potapov EV, Kaufmann F, Müller M, Mulzer J, Falk V. Longest ongoing support (13 years) with magnetically levitated left ventricular assist device. ASAIO J. 2020;66:e121-2.

3. Krabatsch T, Potapov E, Stepanenko A, Schweiger M, Kukucka M, Huebler M, et al. Biventricular circulatory support with two miniaturized implantable assist devices. Circulation. 2011;124(11 Suppl):S179-86.

4. German heart report 2020 [article in German]. Accessed October 18, 2021. Available at: https://www.herzstiftung.de/system/files/2021-06/DeutscherHerzbericht-2020.pdf

5. Kirklin JK, Naftel DC, Pagani FD, Kormos RL, Stevenson LW, Blume ED, et al Seventh INTERMACS annual report: 15,000 patients and counting. J Heart Lung Transplant. 2015;34:1495-504.
6. Copeland JC, Copeland H, Gustafson M, Mineburg N, Covington D, Smith RG, et al. Experience with more than 100 total artificial heart implants. J Thorac Cardiovasc Surg. 2012;143:727-34.

7. González-Vílchez F, Almenar-Bonet L, Crespo-Leiro MG, Segovia-Cubero J, Gonzalez-Costello J, Del Prado JMA, et al; Spanish Heart Transplant Teams Spanish Heart Transplant Registry. 30th official report of the Spanish Society of Cardiology working group on heart failure (1984-2018). Rev Esp Cardiol (Engl Ed). 2019;72:954-62.

8. EuroStat. First population estimates: EU population in 2020 at almost 448 million: More deaths than births [press release in German]. Accessed October 18, 2021. Available at: https://ec.europa.eu/eurostat/documents/2995521/ 11081097/3-10072020-AP-DE.pdf/7f863daa-c1ac-758f-e82b-954726c4621f

9. Shah P, Ha R, Singh R, Cotts W, Adler E, Kiernan M, et al. Multicenter experience with durable biventricular assist devices. J Heart Lung Transplant. 2018;37: 1093-101.

10. Eulert-Grehn JJ, Lanmüller P, Schönrath F, Solowjowa N, Muller M, Mulzer J, et al. Two implantable continuous-flow ventricular assist devices in a biventricular configuration: technique and results. Interact Cardiovasc Thorac Surg. 2018; 27:938-42.

11. Potapov EV, Saito T, Carpentier A, Hetzer R, Krabatsch T. Long-term follow-up of a patient with Uhl anomaly after biologic and mechanical circulatory support. J Thorac Cardiovasc Surg. 2015;149:e115-6.

12. Bernhardt AM, De By TM, Reichenspurner H, Deuse T. Isolated permanent right ventricular assist device implantation with the HeartWare continuousflow ventricular assist device: first results from the European registry for patients with mechanical circulatory support. Eur J Cardiothorac Surg. 2015; 48:158-62.

13. Teuteberg J, Cleveland JC Jr, Cowger J, Higgins RS, Goldstein DJ, Keebler M, et al. The Society of Thoracic Surgeons intermacs 2019 annual report: the changing landscape of devices and indications. Ann Thorac Surg. 2020;109: 649-60.

14. Mehra MR, Uriel N, Naka Y, Clevelad JC Jr, Yuzefpolskaya M, Salerno CT, et al. A fully magnetically levitated left ventricular assist device - final report. $N$ Engl J Med. 2019;380:1618-27.

15. Kormos RL, Cowger J, Pagani FD, Teuteberg JJ, Goldstein DJ, Jacobs JP, et al. The Society of Thoracic Surgeons intermacs database annual report: evolving indications, outcomes, and scientific partnerships. J Heart Lung Transplant. 2019; 38:114-26.

16. Han JJ. Aeson-The Carmat total artificial heart is approved for enrollment in the United States. Artif Organs. 2021;45:445-6.

17. Morshuis M, Rojas SV, Hakim-Meibodi K, Razumov A, Gummert JF, Schramm R. Heart transplantation after SynCardia ${ }^{\circledR}$ total artificial heart implantation. Ann Cardiothorac Surg. 2020;9:98-103.

18. Torregrossa G, Morshuis M, Varghese R, Hosseinin L, Vida V, Tarzia V, et al. Results with SynCardia total artificial heart beyond 1 year. ASAIO J. 2014;60: 626-34.

19. Slaughter MS, Rogers JG, Milano CA, Russell SD, Conte JV, Feldman D, et al. Advanced heart failure treated with continuous-flow left ventricular assist device. N Engl J Med. 2009;361:2241-51.

20. Cleveland JC Jr, Naftel DC, Reece TB, Murray M, Antaki J, Pagani FD, et al. Survival after biventricular assist device implantation: an analysis of the Interagency Registry for Mechanically Assisted Circulatory Support database. J Heart Lung Transplant. 2011;30:862-9.

21. Shehab S, Macdonald PS, Keogh AM, Kotlyar E, Jabbour A, Robson D, et al. Long-term biventricular HeartWare ventricular assist device support-case series of right atrial and right ventricular implantation outcomes. J Heart Lung Transplant. 2016;35:466-73.

22. Tran HA, Pollema TL, Silva Enciso J, Greenberg BH, Barnard DD, Adler ED, et al. Durable biventricular support using right atrial placement of the HeartWare HVAD. ASAIO J. 2018;64:323-7.

23. Lavee J, Mulzer J, Krabatsch T, Marasco S, McGiffin D, Garbade J, et al. An international multicenter experience of biventricular support with HeartMate 3 ventricular assist systems. J Heart Lung Transplant. 2018;37:1399-402.

24. McGiffin D, Kure C, McLean J, Marasco S, Bergin P, Jare JL, et al. The results of a single-center experience with HeartMate 3 in a biventricular configuration. $J$ Heart Lung Transplant. 2021;40:193-200.

Key Words: right ventricle, heart failure, mechanical circulatory support, ventricular assist device 